The following paper posted here is not the official IEEE published version. The final published version of this paper can be found in the Proceedings of the IEEE Aerospace Conference (2006 : Big Sky, Montana):9pp.

Copyright (c) 2006 IEEE.

Personal use of this material is permitted. However, permission to reprint/republish this material for advertising or promotional purposes or for creating new collective works for resale or redistribution to servers or lists, or to reuse any copyrighted component of this work in other works must be obtained from the IEEE. 


\title{
Orbital Payload Delivery Using Hydrogen and Hydrocarbon Fuelled Scramjet Engines
}

\author{
M. R. Tetlow \\ School on Mechanical Engineering \\ The University of Adelaide \\ Adelaide 5005 \\ $++61883033360$ \\ matthew.tetlow@adelaide.edu.au \\ C.J. Doolan \\ School on Mechanical Engineering \\ The University of Adelaide \\ Adelaide 5005 \\ ++61883038261 \\ con.doolan@adelaide.edu.au
}

\begin{abstract}
This paper compares the performance of two different launch systems; one with a hydrogen fuelled scramjet stage and one with a hydrocarbon fuelled scramjet stage. The two launch systems are optimized with respect to payload delivery capability and then compared, assuming a fixed launch mass. A rocket powered booster is used to achieve the required scramjet ignition conditions and a rocket powered orbital stage is used to accelerate the payload from scramjet shut-down to low earth orbit.
\end{abstract}

The trajectory simulator includes a full spheroidal, rotating earth model, a fourth order gravitation model and an MSISE93 atmosphere model. A gradient projection optimization routine is used to achieve an optimal solution using a set of time referenced vertical accelerations as optimization parameters. Hypersonic engine performance is determined using a quasi-one-dimensional scramjet model.

Results show that a hydrogen powered scramjet launch system outperforms a hydrocarbon powered system due to its higher specific impulse and peak Mach Number. While payload mass fractions are shown to be favorable, the high structural requirements of the scramjet imply that reusability is a key characteristic to make them financially viable. Trajectories were found to be dominated by their lift requirements, which outweighed any performance advantage for hydrocarbon fuels in terms of their better storage capability.-

\section{TABLE OF CONTENTS}

1. INTRODUCTION ...........................................1

2. VEHICLE DESCRIPTION ................................2

3. SIMULATION AND OPTIMIZATION....................4

4. MisSiON PROFILE............................................5

5. TRAJECTORY PROFILES ................................5

6. MASS ESTIMATION .......................................6

7. DISCUSSION............................................... 7

8. CONCLUSIONS ..............................................7

9. REFERENCES ..............................................8

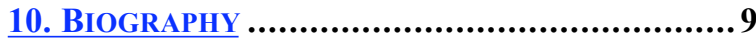

\section{INTRODUCTION}

With the recent success of supersonic combustion ramjet (scramjet) atmospheric test flights [1,2], it is becoming increasingly likely that hypersonic air breathing engines will be utilised for payload delivery to orbit. Scramjets have the advantage of burning atmospheric oxygen instead of an onboard oxidizer, as conventional rockets do. This not only reduces the size and mass of the vehicle but also increases the specific impulse by an order of magnitude [3]. These two factors make scramjets attractive to launch providers as they have the potential to drive launch costs down. There are still many hurdles to overcome, such as control, aerodynamic heating and combustion issues, but their use in future space launch systems is promising.

A number of fuel types have been investigated in the literature for use in scramjet propulsion systems, from solid [4] and liquid [5] hydrocarbon based fuels to various phases of hydrogen [6]. Hydrocarbon fuels have a distinct advantage over hydrogen with respect to storage. Hydrocarbons have up to 11 times the storage density of hydrogen [7] making the tanks and therefore the entire vehicle much smaller compared with an equivalent propellant mass hydrogen powered vehicle. Hydrogen does 
however have a significantly higher specific impulse [3], [5]. In addition, hydrogen is the only fuel likely to deliver net positive levels of thrust at near orbital velocities [7]. Hydrogen fuelled scramjets are believed to have an operating range of between Mach 5 and Mach 15 [3], with hydrocarbon fuelled scramjets expected to reach about Mach $10[7]$.

Either hydrogen or hydrocarbon fuels would be suitable for a powered scramjet flight segment; however, the mission profiles would be considerably different. Due to an operating limit of Mach 10 for hydrocarbon fuelled engines [7], the scramjet flight segment would be considerably shorter than that for a hydrogen fuelled vehicle. This would reduce the size of the scramjet stage due to its shorter burn time, thereby lower fuel mass requirement, and the fact that it has a higher fuel storage efficiency compared to a hydrogen fuelled scramjet. It would, however, also reduce the velocity increment contribution at the high specific impulse values possible using scramjet propulsion.

The limited operating range of scramjets means that another type of propulsion system is required, in addition to the scramjet, to achieve orbit from a stationary state. There are a number of possible solutions to this problem including rocket and/or air breathing systems or even a combination of the two. Rocket propulsion systems have the advantage of being able to operate over all flight regimes encountered between a stationary state and orbit. Unfortunately, even the most efficient rocket engines are restricted to a specific impulse of around 430s [8] making them considerably less efficient than air breathing propulsion systems.

Turbojet and ramjet propulsion systems can achieve high specific impulse values, typically up to $7000 \mathrm{~s}$ and $4000 \mathrm{~s}$ respectively [3], however, they are limited to velocities at or below that at which scramjets will ignite. This has led to a number of studies into combined cycle propulsion systems. Two of the best known examples of such combined cycle systems are the NASP vehicle [9] and the SÄNGER vehicle [10]. These vehicles rely not only on pure scramjet operation, but on complex systems capable of changing to suit many operating conditions from turbojet through ramjet, scramjet and finally to rocket mode to achieve orbit. Although these systems may provide a better solution from a performance point of view, their complexity makes them less attractive in the near future. It was therefore decided to use a pure scramjet powered stage, with conventional rockets providing propulsion before and after the scramjet stage.

Air breathing scramjet engines require a certain minimum static pressure to maintain supersonic combustion. This is achieved by ensuring that the flight vehicle maintains a dynamic pressure above a minimum value of $9.5 \mathrm{kPa}$ [9]. For the current study, the scramjet operating range was chosen to be well within the operating limits discussed above, with ignition occurring at Mach 7 and shut-down occurring at Mach 15 and Mach 10 for the hydrogen and hydrocarbon fuelled vehicles respectively. This equates to a dynamic pressure range between $175 \mathrm{kPa}$ and $50 \mathrm{kPa}$ over the scramjet powered flight phases. Scramjet ignition occurs at Mach 7 as successful flight tests have been demonstrated at this Mach Number [2] [1].

A number of different scramjet body configurations have been investigated in the literature in both ballistic [11] and lifting body configurations [12]. As a lifting trajectory is desirable and scramjet powered waverider configuration vehicles have been developed and tested [2], it was decided to use a waverider lifting body configuration in this study. According to [9], the angle of attack of the scramjet intake should be limited to around $5^{\circ}$.

In order to assess the performance of a new launch system, a comparison will need to be performed with existing launch systems. As launch systems vary considerably in start mass and payload delivery capability, the payload mass fraction will be used as a comparison measure. Large launch vehicles tend to have improved payload mass fractions due to their improved propellant mass fractions [8]. Vehicles with similar payload capabilities will therefore be used for the comparison.

Table 1. Current launch vehicle performance [8]

\begin{tabular}{|l|l|l|}
\hline Launch vehicle & $\begin{array}{l}\text { Payload mass (mass } \\
\text { fraction) }\end{array}$ & $\begin{array}{l}\text { LEO altitude } \\
\text { and inclination }\end{array}$ \\
\hline ASLV & $150 \mathrm{~kg}(0.36 \%)$ & $400 \mathrm{~km}$ at $43^{\circ}$ \\
\hline M-3S11 & $780 \mathrm{~kg}(1.26 \%)$ & $185 \mathrm{~km}$ at $31^{\circ}$ \\
\hline Long March CZ1D & $720 \mathrm{~kg}(0.9 \%)$ & $200 \mathrm{~km}$ at $28^{\circ}$ \\
\hline Start-1 & $360 \mathrm{~kg}(0.6 \%)$ & $400 \mathrm{~km}$ at $90^{\circ}$ \\
\hline
\end{tabular}

Table 1 shows that payload mass fractions for this class of launch vehicle are approximately $1 \%$ for a $200 \mathrm{~km}$ circular orbit. As expected, higher altitude orbits result in lower payload mass fractions. A $200 \mathrm{~km}$ circular orbit will be used for comparison for the present study and a payload mass fraction of $0.9 \%$ (corresponding to the Long March CZ1D vehicle) will be the benchmark for comparison.

\section{VEHICLE DESCRIPTION}

The launch system developed in this study consists of a two stage rocket powered booster and a scramjet powered waverider. The final rocket stage is housed in a payload bay inside the waverider. The total launch mass of the system was taken to be $9300 \mathrm{~kg}$. 


\section{Booster stages}

The booster stages were required to achieve scramjet ignition conditions from a ground launch. A two stage booster was chosen as this allowed the correct altitude and flight path angle to be reached while not spending a significant amount of time in the high density lower altitudes. Because the required altitude of $25 \mathrm{~km}$ at zero degree flight path angle is relatively low, a single stage, non-restartable booster would require a very shallow ascent trajectory to reach the required scramjet conditions. This type of trajectory would have a significantly higher integrated drag loss due to the high velocity at low altitudes.

From the required propellant mass, the fully fuelled mass, without payload, was estimated using a structure mass fraction of 0.18 . The first stage booster had a propellant mass of $2000 \mathrm{~kg}$ and the second stage booster a propellant mass of $4000 \mathrm{~kg}$.

The propulsion system was modeled using a propellant mass flow rate vs. time profile. The specific impulse (Isp) at specific altitudes was calculated using equation 1 .

$$
I s p=I s p_{s l}+\frac{P(h)}{P_{0}}\left(I s p_{v a c}-I s p_{s l}\right)
$$

Where $P(h)$ is the local atmospheric pressure at the current altitude, $P_{0}$ is the local atmospheric pressure at sea level and $I s p_{s l}$ and $I s p_{v a c}$ are the specific impulse values at sea level and in vacuum respectively.

The aerodynamic coefficients for the boosters were calculated using a model developed for a conceptual launch vehicle called ArianeX [13]. The model provides lift and drag coefficients as a function of Mach Number at zero angle of attack.

\section{Scramjet (waverider) stage}

Waveriders are hypersonic vehicles that 'ride' the shockwave they produced during flight, thereby improving their lift to drag ratio [12]. An example of a waverider vehicle shape is shown in Figure 1. Note that the model shown in Figure 1 does not include a propulsion system.

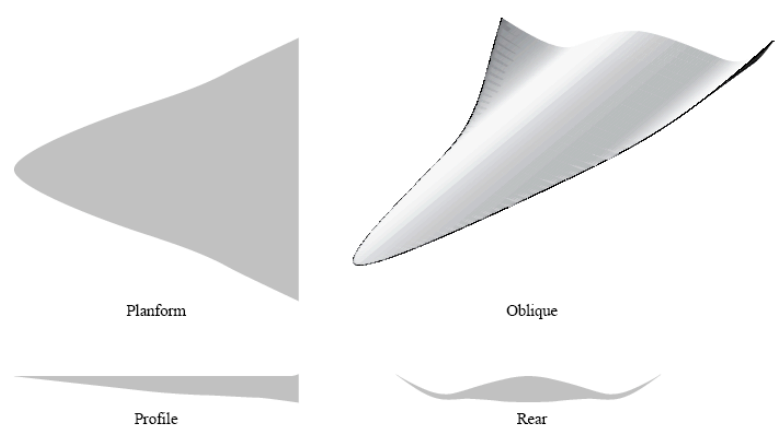

Figure 1. Waverider vehicle [12]

When the propulsion system is integrated into the waverider, Figure 2 shows the lift to drag ratio has a maximum value of around 4 [12].

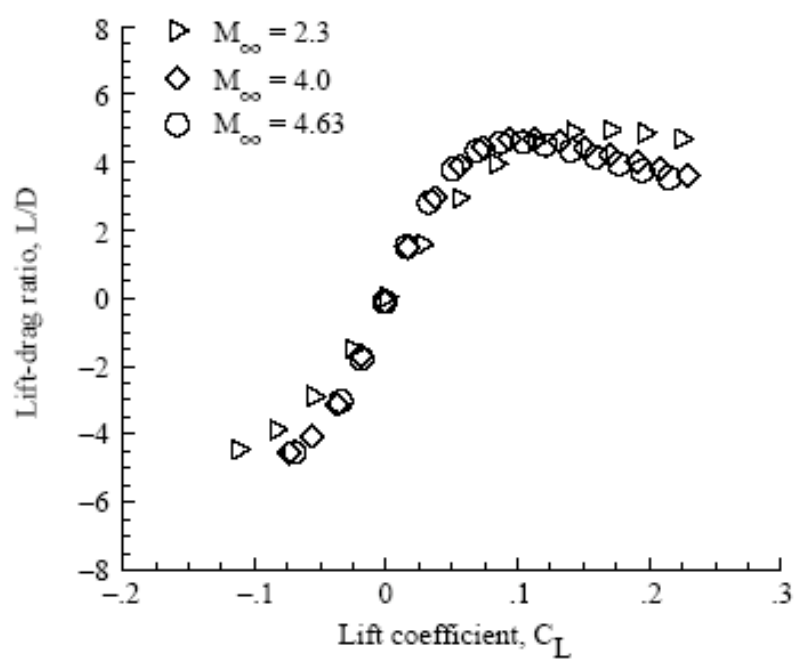

Figure 2. Lift to drag ratio for a waverider with an integrated propulsion system [12]

The aerodynamic parameters for the waverider, with an integrated scramjet propulsion system, were taken from [12] and [6], providing drag and lift coefficients as a function of Mach No. and angle of attack. Data was only available up to Mach 6, after which the aerodynamic data was extrapolated.

From the predetermined waverider start mass of $2000 \mathrm{~kg}$ and the average density for a hydrogen fuelled waverider, including payload, of $124 \mathrm{~kg} / \mathrm{m}^{3}$ [7] the volume of the vehicle could be estimated. From the required volume, equation 2 was used to approximate the aerodynamic reference area $\left(A_{\text {ref }}\right)$. 


$$
A_{\text {ref }}=c V^{\frac{2}{3}}
$$

Where $V$ is the vehicle volume and $c$ is the volumetric efficiency, which ranges between 0.2 and 0.8 for hypersonic cruise vehicles [7], [14]. A value of 0.3 was used in this paper as this represents a mid-range value.

A quasi-one-dimensional flow solver is used to model the flow properties within the scramjet combustor in order to calculate its overall thrust and specific impulse. Following the approach of O'Brien et al. [15], a series of ordinary differential equations (ODEs) were derived to describe the fluid motion within the scramjet duct. In this study, additional equations were added to take into account boundary layer growth along the combustor walls. It is assumed that the supersonic flame is piloted at injection, thereby ensuring combustion is controlled by mixing rather than by chemical kinetics.

The equations solved are:

$$
\begin{aligned}
& \frac{\mathrm{d} A}{\mathrm{~d} x}=\frac{d A_{o}}{d x}-P_{w} \frac{0.2145 M^{0.375}}{\operatorname{Re}_{x}^{0.166}}(0.08801 M+0.06365) \\
& \left.\frac{\mathrm{d} U}{\mathrm{~d} x}=\frac{1}{\alpha}\left[-\frac{1}{A} \frac{\mathrm{d} A}{\mathrm{~d} x}+\left\{1+\gamma M^{2}-\frac{h_{o}}{h}+\frac{C_{p} T_{f}}{h}\right\} \frac{1}{\dot{m}} \frac{\mathrm{d} \dot{m}}{\mathrm{~d} x}+\frac{\mathrm{d} \dot{m}}{\mathrm{~d} x} \frac{\eta_{C} Q_{R}}{\dot{m}}\right\}+2 \frac{c_{f}}{\mathrm{D}}\left\{\gamma M^{2}-\frac{c_{p}\left(T_{a w}-T_{w}\right)}{h \operatorname{Pr}^{2 / 3}}\right\}\right] \\
& \frac{\mathrm{d} \rho}{\mathrm{d} x}=\rho\left[\frac{1}{\dot{m}} \frac{\mathrm{d} \dot{m}}{\mathrm{~d} x}-\frac{1}{U} \frac{\mathrm{d} U}{\mathrm{~d} x}-\frac{1}{A} \frac{\mathrm{d} A}{\mathrm{~d} x}\right] \\
& \frac{\mathrm{d} p}{\mathrm{~d} x}=-\gamma p M^{2}\left[\frac{1}{U} \frac{\mathrm{d} U}{\mathrm{~d} x}+\frac{1}{2}\left(\frac{4 c_{f}}{\mathrm{D}}\right)+\frac{1}{\dot{m}} \frac{\mathrm{d} \dot{m}}{\mathrm{~d} x}\right] \\
& \frac{\mathrm{d} T}{\mathrm{~d} x}=T\left[\frac{1}{p} \frac{\mathrm{d} p}{\mathrm{~d} x}-\frac{1}{\rho} \frac{\mathrm{d} \rho}{\mathrm{d} x}\right] \quad h=C_{p} T \quad C_{p}=\frac{\gamma R}{M W(\gamma-1)} \\
& \alpha=\frac{1}{U}\left[1-\gamma M^{2}+\frac{U^{2}}{h}\right] \quad h \quad
\end{aligned}
$$

The solver assumes ideal gas behavior and that a constant ratio of specific heats (_) exists within the duct. Combustion takes the form of releasing heat proportional to the mixing rate $\mathrm{d} \dot{m} / \mathrm{d} x$ multiplied by the heat of combustion $Q_{R}$. The geometric area of the duct, $A_{o}$, is corrected by the boundary layer displacement thickness on the duct walls to produce the working area, $A$ using an empirical correlation [16]. Heat loss through the walls is related to the skin friction coefficient $\left(c_{f}\right)$ through the Reynold's analogy and is dependent on the adiabatic and actual wall temperatures ( $T_{a w}$ and $T_{w}$ respectively). The Prandtl number, $P r$, is assumed constant and equal to 0.72 . The pressure $(p)$ and temperature $(T)$ equations were derived using the differential forms of the conservation of mass and ideal gas equations. The specific heat $C_{p}$ is related to the gas constant, $R$, and the molecular weight of the mixture, $M W$. Thrust is calculated by integrating the pressure multiplied by the axial area increment along the combustor. Incorporated into this integration are the skin friction forces that act to retard scramjet motion.

The combustor inlet conditions are calculated using an idealized hypersonic inlet model. This incorporates inlet total pressure loss through a kinetic energy efficiency factor, which is set to 0.96 for this study.

The system of equations (3) is solved using the Lawrence Livermore ODEPACK system of solving stiff ODEs [11] and programming was performed using FORTRAN 90.

More complete documentation of this scramjet combustor model is documented in [17] where it is shown the model correctly predicts the pressure rise in experimental scramjet combustors. An exponential mixing model is used to release heat at the correct rate along the combustor which is also described in [17].

There are many loss mechanisms that limit scramjet propulsive performance. These include mixing losses, combustion losses, Rayleigh effects and other entropy raising mechanisms that occur in the combustor duct. While it is difficult to incorporate these losses individually in the quasi-one-dimensional scramjet model, a global combustion efficiency $\left(\eta_{C}\right)$ is simple to implement and is used instead. The combustion efficiency limits the amount of energy available for propulsion and is set to 0.5 in accordance with the scramjet propulsion estimates of Kerrebrock [18].

\section{Orbital stage}

The orbital stage is a separate rocket stage that would be deployed from the scramjet payload bay and accelerate the payload from scramjet shut-down conditions to the required $200 \mathrm{~km}$ circular orbit. A structural mass fraction of 0.15 was used for the orbital stage with a specific impulse of 324s. These values were taken from the upper stage of the Japanese H2 launch vehicle [8].

\section{Simulation AND OPTIMIZATION}

The software used was a Fortran based code, originally developed at the Space Systems Institute in Stuttgart, Germany, and then modified for the purposes of this study. The dynamic equations were taken from [19] and describe a 3 degree of freedom trajectory over a rotating earth model, using a 4th order Runge-Kutta integration technique. A spheroidal earth model was used to determine the radius of the Earth at given latitudes. A 4th order gravitational model [20] was implemented to approximate the Earth's gravitational field, and the atmospheric parameters were calculated using the Mass Spectrometer Incoherent Scatter 1993 (MSISE 93) atmosphere model [21]. 
A gradient projection optimization routing was used to optimize the trajectory based on a minimum fuel consumption trajectory. The trajectory was parameterized using a set of vertical accelerations as a function of time. The lift force required was calculated using equation 4 .

$$
L=\frac{m}{g-a_{v e r t}(t)}
$$

Where $L$ is the lift force, $m$ is the vehicle's current mass, $g$ is the local gravitational force and $a_{v e r t}$ is the vertical component of acceleration as a function of time. This acceleration profile produces the fuel minimum trajectory that achieves the correct target conditions.

Using equation 4, the required lift force can be determined. The waverider aerodynamic model is then used to determine the required angle of attack and the resulting drag force.

\section{Mission ProfiLe}

The mission involves launching a vehicle capable of delivering a payload to a $200 \mathrm{~km}$ circular orbit from the ground. This requires an inertial velocity of $7784.3 \mathrm{~m} / \mathrm{s}$ at an altitude of $200 \mathrm{~km}$ and a zero degree flight path angle. As this is an orbit with an inclination of $-60^{\circ}$, the equivalent local horizontal velocity is $8202.9 \mathrm{~m} / \mathrm{s}$ at the same conditions.

The first stage booster burns from the launch pad for 10 seconds to clear the dense lower altitude atmosphere. After a $45 \mathrm{~s}$ coast phase the second booster stage ignites and accelerates the scramjet to an altitude of around $25 \mathrm{~km}$, a Mach Number of 7 and a zero degree flight path angle.

For the hydrogen fuelled vehicle, the scramjet burns for approximately $345 \mathrm{~s}$ to achieve an altitude of $40 \mathrm{~km}$, a local horizontal velocity of $4831 \mathrm{~m} / \mathrm{s}$ (Mach 15) and a flight path angle of 1.4 degrees. After scramjet shut-down, the angle of attack is set to 20 degrees and the vehicle climbs to an altitude of $58.13 \mathrm{~km}$, a local horizontal velocity of $4580 \mathrm{~m} / \mathrm{s}$ and a flight path angle of zero degrees. The upper stage is then released, which ignites once for injection at perigee into a $58.18 \mathrm{~km} \times 200 \mathrm{~km}$ Low Earth Transfer Orbit (LTO). After a coast to apogee, a second burn injects the payload into a $200 \mathrm{~km}$ circular orbit.

For the hydrocarbon (Jet A) fuelled vehicle, the scramjet burns for approximately $150 \mathrm{~s}$ to achieve an altitude of $33 \mathrm{~km}$, a local horizontal velocity of $3096 \mathrm{~m} / \mathrm{s}$ (Mach 10) and a flight path angle of 1.8 degrees. After scramjet shut-down, the angle of attack is again set to 20 degrees and the vehicle climbs to an altitude of $44.94 \mathrm{~km}$, a local horizontal velocity of $2840 \mathrm{~m} / \mathrm{s}$ and a flight path angle of zero degrees. The upper stage is then released, which ignites once for injection at perigee into a $44.94 \mathrm{~km} \times 200 \mathrm{~km}$ LTO. After a coast to apogee, a second burn injects the payload into a $200 \mathrm{~km}$ circular orbit.

\section{Trajectory Profiles}

Due to the different operating conditions of the two scramjets, their mission profiles will differ significantly. This section will show the mission profiles from the ignition of the first stage booster to the payload separation from the waverider. All conditions are shown in the local horizontal frame. It should be noted that the burn of the orbital stage is not shown.

\section{Hydrogen fuelled waverider}

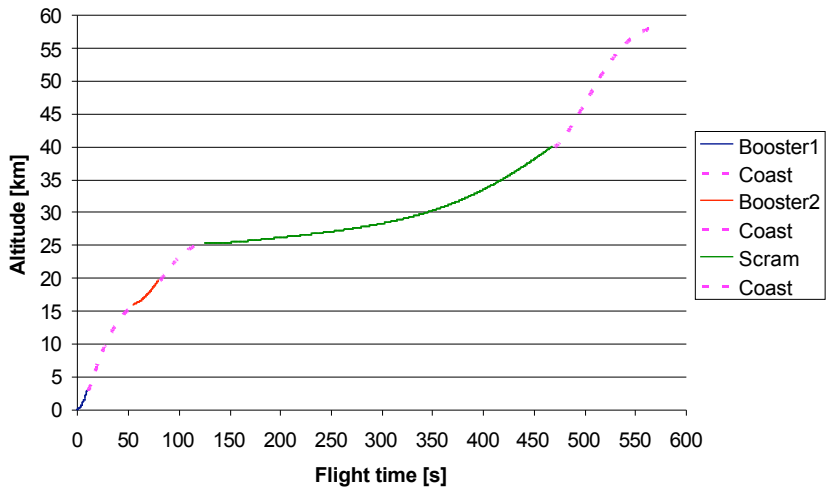

Figure 3. Altitude profile for the hydrogen fuelled vehicle

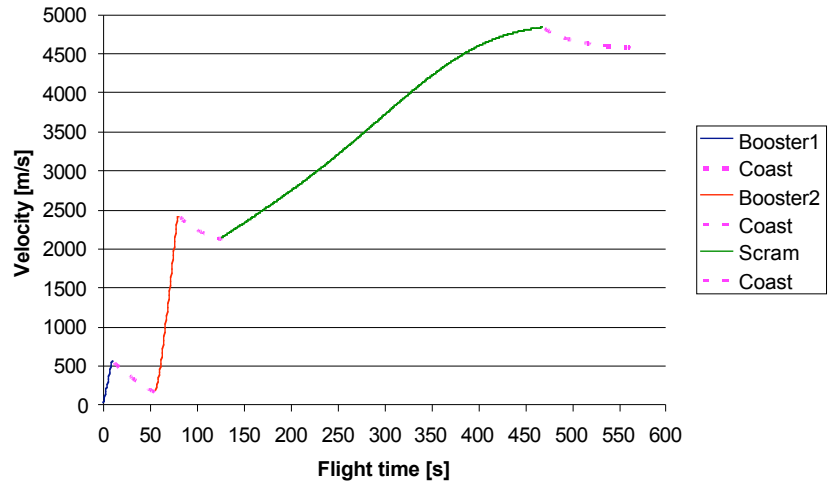

Figure 4. Velocity profile for the hydrogen fuelled vehicle

Figure 3 and Figure 4 show the altitude and velocity profiles, respectively, for the hydrogen fuelled scramjet vehicle. The two booster stages are seen to accelerate the waverider to a velocity of $2140 \mathrm{~m} / \mathrm{s}$ at an altitude of $25 \mathrm{~km}$. The scramjet is then ignited and accelerates the waverider to a velocity of $4832 \mathrm{~m} / \mathrm{s}$ at an altitude of $40 \mathrm{~km}$. During the 
scramjet burn the angle of attack was kept below $6^{\circ}$ and the dynamic pressure range was between 50 and $126 \mathrm{kPa}$. At scramjet shut-down, the angle of attack was set to $20^{\circ}$. This is seen by the increase in flight path angle and the drop in velocity at approximately 470 s flight time. This was done to achieve as high an altitude as possible at the ignition of the orbital stage, thereby minimizing the dynamic pressure on the payload.

\section{Hydrocarbon fuelled waverider}

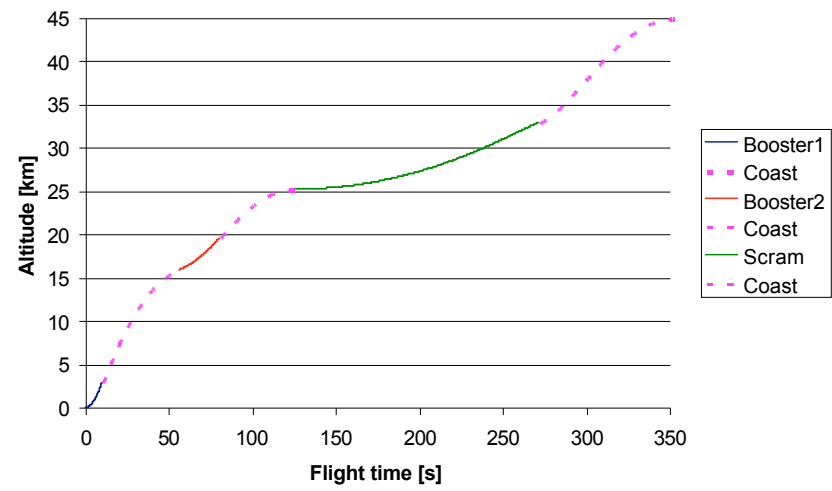

Figure 5. Altitude profile for the hydrocarbon fuelled vehicle

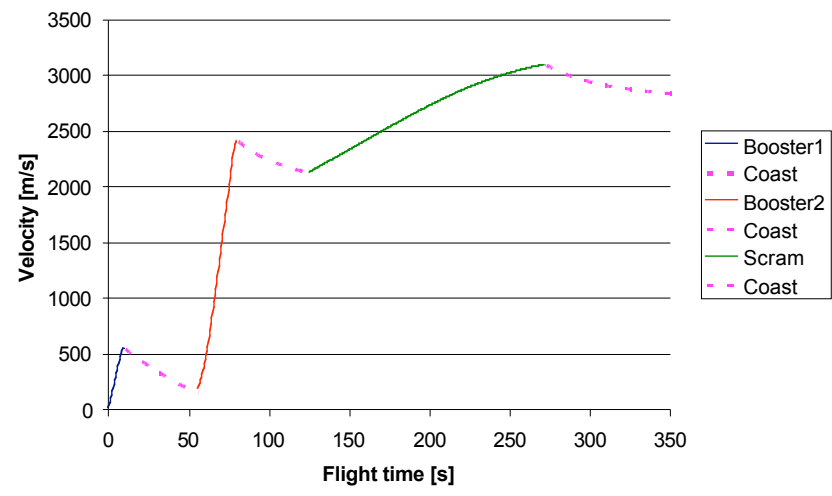

Figure 6. Velocity profile for the hydrocarbon fuelled vehicle

Figure 5 and Figure 6 show the altitude and velocity profiles, respectively, for the hydrocarbon fuelled scramjet vehicle. Again, the two booster stages are seen to accelerate the waverider to a velocity of $2140 \mathrm{~m} / \mathrm{s}$ at an altitude of $25 \mathrm{~km}$. The scramjet is then ignited and accelerates the waverider to a velocity of $3096 \mathrm{~m} / \mathrm{s}$ at an altitude of $33 \mathrm{~km}$. During the scramjet burn the angle of attack was kept below $6^{\circ}$ and the dynamic pressure range was between 58 and $114 \mathrm{kPa}$. Again, at scramjet shut-down the angle of attack was set to $20^{\circ}$ to maximize the orbital stage ignition altitude.
Table 2. Conditions at orbital stage release

\begin{tabular}{|l|c|c|}
\hline & $\begin{array}{c}\text { Hydrogen fuelled } \\
\text { vehicle }\end{array}$ & $\begin{array}{c}\text { Hydrocarbon fuelled } \\
\text { vehicle }\end{array}$ \\
\hline Mass & $1684 \mathrm{~kg}$ & $1741 \mathrm{~kg}$ \\
\hline Altitude & $58.13 \mathrm{~km}$ & 44.94 \\
\hline Velocity & $4580 \mathrm{~m} / \mathrm{s}$ & $2840 \mathrm{~m} / \mathrm{s}$ \\
\hline
\end{tabular}

Table 2 shows the states just before the orbital stage is released. The mass shown includes the mass of the dry waverider and the orbital stage.

\section{Mass Estimation}

As was discussed in section 2 both the hydrogen and hydrocarbon fuelled waveriders had the same start mass of two tonnes. From the point mass trajectory optimization, the fuel mass required for the scramjet burn could be calculated. Based on the fuel mass fraction of 0.58 and 0.7 [7] for hydrogen and hydrocarbon fuelled vehicles respectively, the structure mass required for a scramjet without payload could be calculated using equation 5 .

$$
\varepsilon=\frac{m_{\text {fuel }}}{m_{\text {total }}}
$$

Where _ is payload mass fraction and $m$ is mass.

Average payload densities, based on current launcher payload bay volumes and masses, vary considerably depending on the launch vehicle. A representative payload mass to volume ratio (average density) is that of the Start-1 rocket, which is approximately $132 \mathrm{~kg} / \mathrm{m}^{3}$ [8]. Assuming an equivalent relationship exists between fuel and stage mass, and payload and stage mass, the structure required to house the scramjet payload can be estimated. A value of 0.6 was assumed for the payload mass to stage mass, based on the bounds of 0.58 for a $82 \mathrm{~kg} / \mathrm{m}^{3}$ substance (hydrogen) and 0.7 for an $800 \mathrm{~kg} / \mathrm{m}^{3}$ substance (Jet A).

Hence, the waverider mass was estimated based on the fuel and the payload storage requirements. The scramjet dry mass in Table 3 represents this combined mass. Note that the dry masses are different for the hydrogen and Jet A powered vehicles. This is due to the fact that the fuel storage density for the Jet A vehicle is better than that for the hydrogen fuelled vehicle. 
The remaining mass, after subtracting the scramjet dry mass and the fuel mass from the start mass, represents the mass available for the orbital stage. Considering the _ $V$ requirements to achieve orbit from the conditions stated in

Table 2 and the performance measures of the orbital stage discussed in section 2, the payload masses for the two vehicles can be estimated.

Table 3. System mass comparison

\begin{tabular}{|l|c|c|}
\hline & $\begin{array}{c}\text { Hydrogen } \\
\text { fuelled scramjet }\end{array}$ & $\begin{array}{c}\text { Hydrocarbon } \\
\text { fuelled scramjet }\end{array}$ \\
\hline Scramjet initial mass & $2000 \mathrm{~kg}$ & $2000 \mathrm{~kg}$ \\
\hline Scramjet fuel mass & $316 \mathrm{~kg}$ & $258.8 \mathrm{~kg}$ \\
\hline Scramjet dry mass & $1000 \mathrm{~kg}$ & $918.3 \mathrm{~kg}$ \\
\hline Upper stage mass & $684 \mathrm{~kg}$ & $822.9 \mathrm{~kg}$ \\
\hline Payload mass & $108.5 \mathrm{~kg}$ & $36.0 \mathrm{~kg}$ \\
\hline
\end{tabular}

The payload masses shown in Table 3 equate to a payload mass fraction of $1.17 \%$ and $0.38 \%$ for the hydrogen and hydrocarbon powered vehicles respectively.

\section{DisCUSSION}

The first observation is that the payload mass fraction for the launch systems with a hydrogen powered scramjet stage is only slightly higher than those for fully rocket powered launch systems. The reason for this is that although the specific impulse for a scramjet powered stage is considerably higher than that for a rocket stage, the fuel mass fraction is lower. This means that a similar total stage mass is required, but a larger portion of this mass is required for structure in the scramjet powered case. This is due to the lower fuel storage efficiency of waveriders compared to rockets. Recall that a hydrogen powered waverider has a fuel mass fraction of 0.58 while hydrocarbon fuelled waveriders can achieve 0.7 . A rocket stage can have a fuel mass fraction of up to 0.94 [22].

This observation implies that if the launch system is designed to be an expendable system, a scramjet stage would not be a financially viable option as vehicle structure is much more expensive than propellant. If a scramjet powered flight segment were to be considered in a launch system design, at least the scramjet stage would need to be reusable.
Although previous rocket powered launch systems, such as the Space Shuttle, suggest that reusable launch systems are not financially beneficial [8], a scramjet powered stage may be easier to make reusable due to the few moving parts in the propulsion system. The scramjet stage proposed in this design is also suborbital so would not have to endure an orbital reentry flight, again making reusability easier to achieve.

When comparing the hydrogen and Jet A powered scramjet stages it can clearly be seen that the hydrogen powered vehicle has a significant payload advantage over the Jet A powered vehicle. Although the Jet A powered vehicle requires a lower dry mass to store its fuel, its Mach 10 operating limit and lower specific impulse overrides its dry mass advantage. The payload mass fraction of the launch system with a Jet A powered waverider is seen to be below that of a fully conventional rocket powered launch system.

Not only does the launch system with the hydrogen powered waverider have an improved payload mass fraction, it also uses considerably less stored propellant during its ascent than a fully rocket powered system.

An observation made during the trajectory analysis was that the minimum dynamic pressure limit of $10 \mathrm{kPa}$ for the scramjet operation was not reached. The minimum dynamic pressure required to lift the weight of the vehicle was higher than the engine operating limit at the end of flight. In order to overcome this absence of lift at high altitude, the lifting area of the scramjet could be increased. This would, however, increase the volume and mass of the vehicle.

The advantage of a Jet A fuelled waverider of an improved fuel storage density is not beneficial to the mission profile as the vehicle size and therefore volume cannot be reduced due to the lift requirements.

\section{Conclusions}

A similar payload mass fraction was found to be achievable using a launch system with a scramjet powered stage, and a fully rocket powered system. Although less propellant was required for the scramjet powered stage, the required structure mass was higher than that for a rocket powered stage.

This implies that in order to make a launch system with a scramjet powered stage economically feasible, at least the scramjet stage needs to be reusable. Scramjet powered stages may be relatively easy to make reusable due to there being few moving parts in the propulsion system. In addition, the scramjet powered stage would not be required to perform an orbital reentry flight, therefore, would not have stringent thermal protection system requirements. 
For an orbital delivery launch system, a system with a hydrogen powered scramjet stage was found to have a significantly higher payload capability than one with a Jet A powered scramjet stage. This is due to the extended operating range of the hydrogen fuelled vehicle (up to Mach 15) and the higher specific impulse.

The advantage of improved fuel storage density for the Jet A fuelled case was found to not benefit an orbital mission. The reason for this is that insufficient lift is a limiting factor in achieving a desirable orbital stage release condition, so the vehicle volume cannot be reduced as this would reduce its lift capability.

The use of air-breathing propulsion for the Mach 0-7 flight would considerably enhance payload performance, especially for the Jet A case. Similarly, the use of a scramjet/rocket stage in place of the orbital stage would also improve payload capability.

\section{REFERENCES}

1. Boyce, R., S. Gerard, and A. Paull. The HyShot Scramjet Flight Experiment - Flight Data and CFD Calculations Compared. in 12th AIAA International Space Planes and Hypersonic Systems and Technologies. 2003. Norfolk, Virginia: AIAA.

2. Moses, P.L., et al., NASA Hypersonic Flight Demonstrators - Overview, Status, and Future Plans. Acta Astronautica, 2004. 55: p. 619-630.

3. Fortescue, P. and J. Stark, Spacecraft System Engineering. 1995: Wiley.

4. Cohen-Zur, A. and B. Natan, Experimental Investigation of a Supersonic Combustion Solid Fuel Ramjet. Journal of Propulsion and Power, 1998. 14(6): p. 880-889.

5. Savino, R. and G. Pezzella, Numerical Analysis of Supersonic Combustion Ramjet with Upstream Fuel Injection. International Journal for Numerical Methods in Fluids, 2003. 43: p. 165-181.

6. $\quad$ Engelund, W.C., et al. Propulsion System Airframe Integration Issues and Aerodynamic Database Development for the Hyper-X Flight Research Vehicle. in XIV ISOABE Conference. 1999. Florence.

7. Lewis, M.J., Significance of Fuel Selection for Hypersonic Vehicle Range. Journal of Propulsion and Power, 2001. 17(6): p. 1214-1221.

8. Isakowitz, S.J., International Reference Guide to Space Launch Systems `. 1995: AIAA.

9. Moses, P.L., et al. An Airbreathing Launch Vehicle Design with Turbine-Based Low-Speed Propulsion and Dual Mode Scramjet High-Speed Propulsion. in 9th International Space Planes and Hypersonic Systems and Technologies Conference. 1999. Norfolk, VA: AIAA.
10. Kuczera, H., P. Krammer, and P.W. Sacher. SANGER and the German Hypersonics Technology Program - Status Report 1991. in International Astronautical Congress. 1991: International Astronautical Federation.

11. Gaiddon, A., D.D. Knight, and C. Poloni, Multicriteria Design Optimization of a Supersonic Inlet Based upon Global Missile Performance. Journal of Propulsion and Power, 2004. 20(3): p. 542-558.

12. Cockrell, C.E., L.D. Huebner, and D.B. Finley, Aerodynamic Characteristics of Two WaveriderDerived Hypersonic Cruise Configurations. 1996, NASA: Hampton, Virginia.

13. Rahn, M. and U.M. Schoettle, Decomposition Algorithm for Performance Optimization of a Launch Vehicle. Journal of Spacecraft and Rockets, 1996. 33(2): p. 214-221.

14. Stuckey, R.M. and M.J. Lewis, Hypersonic Missile Requirements and Operational Tradeoff Studies. Journal of Spacecraft and Rockets, 2003. 40(2): p. 292-293.

15. O'Brien, T., R. Starkey, and M. Lewis, QuasiOne-Dimensional High Speed Engine Model with Finite Rate Chemistry. Journal of Propulsion and Power, 2001. 17(6): p. 1366-1374.

16. Boyce, R.R., et al., Comparison of Supersonic Combustion Between Impulse and Vitiation-Heated Facilities. Journal of Propulsion and Power, 2000. 16(4): p. 709-717.

17. Doolan, C.J. A Supersonic Combustion Model for Scramjet Vehicle Performance Studies. in 5th AsiaPacific Conference on Combustion. 2005. Adelaide, Australia.

18. Kerrebrock, J.L., Some Readily Quantifiable Aspects of Scramjet Engine Performance. Journal of Propulsion and Power, 1992. 8(5): p. 11161122.

19. Burkhardt, J., REENT6D a Simulation and Optimization Tool for Re-entry Missions. 2000, IRS - Internal report IRS-01B7: Stuttgart.

20. Regan, F.J. and S.M. Anandakrishnan, Dynamics of Atmospheric Reentry. Education Edition. 1993: AIAA.

21. Tetlow, M., Commercial Launch Vehicle Design and Predictive Guidance Development, in School of Mechanical Engineering. 2003, The University of Adelaide: Adelaide.

22. Huzel, D.K. and D.H. Huang, Modern Engineering for the Design of Liquid-Propelled Rocker Engines. Progress in Astronautics and Aeronautics, 1992. 147. 


\section{BIOGRAPHY}

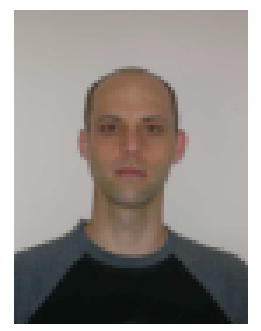

Matthew Tetlow is a post doctoral research fellow at the University of Adelaide, working on the Hyshot project. His main areas of research are vehicle dynamic modeling, trajectory design and optimization, and launch system design. $\mathrm{He}$ is also involved in control system development, GPS systems and hybrid (mechanical) and a $\mathrm{PhD}$. rocket propulsion. $\mathrm{He}$ has a BEng

Con Doolan is a Lecturer in the School of Mechanical Engineering. He has research interests in fluid mechanics and combustion and has worked on a number of projects in propulsion systems. Previously he has worked at the Defence Science and Technology Organisation in the area of Weapons Propulsion and also at the University of Glasgow investigating the aerodynamics of rotorcraft. He has a $\mathrm{BE}$ (mechanical) from the University of Queensland and a PhD from the same institution. 
